\title{
Appropriateness of Lumbar Spine Referrals to a Neurosurgical Service
}

\author{
J. Max Findlay, Nathan Deis
}

\begin{abstract}
Background: Patients with lumbar spine complaints are often referred for surgical assessment. Only those with clinical and radiological evidence of nerve root compression are potential candidates for surgery and appropriate for surgical assessment. This study examines the appropriateness of lumbar spine referrals made to neurosurgeons in Edmonton, Alberta. Methods: Lumbar spine referrals to a group of ten neurosurgeons at the University of Alberta were reviewed over three two month intervals. Clinical criteria for "appropriateness" for surgical assessment were as follows: "Appropriate" referrals were those that stated leg pain was the chief complaint, or those that described physical exam evidence of neurological deficit, and imaging reports (CT or MRI) were positive for nerve root compression. "Uncertain" referrals were those that reported both back and leg pain without specifying which was greater, without mention of neurologic deficit, and when at least possible nerve root compression was reported on imaging. • "Inappropriate" referrals contained no mention of leg symptoms or signs of neurological deficit, and/or had no description of nerve root compression on imaging. Results: Of the 303 referrals collected, 80 (26\%) were appropriate, 92 (30\%) were uncertain and 131 (44\%) were inappropriate for surgical assessment. Conclusions: Physicians seeking specialist consultations for patients with lumbar spine complaints need to be better informed of the criteria which indicate an appropriate referral for surgical treatment, namely clinical and radiological evidence of nerve root compression. Avoiding inappropriate referrals could reduce wait-times for both surgical consultation and lumbar spine surgery for those patients requiring it.
\end{abstract}

RÉSUMÉ: Pertinence de l'orientation de patients présentant une pathologie à la colonne lombaire à un service de neurochirurgie. Contexte : Les patients qui ont des symptômes à la colonne lombaire sont souvent dirigés vers une évaluation chirurgicale. Seulement ceux qui présentent des manifestations cliniques et radiologiques de compression d'une racine nerveuse sont des candidats potentiels à la chirurgie et à une évaluation en vue d'une chirurgie. Cette étude examine le bien fondé des orientations vers des neurochirurgiens à Edmonton, en Alberta, pour des problèmes lombaires. Méthodologie : Les demandes de consultation pour des patients adressés à un groupe de dix neurochirurgiens à l'Université de l'Alberta pour des problèmes lombaires ont été révisées au cours de trois périodes de deux mois. Les critères cliniques pour évaluer le bien fondé d'une évaluation chirurgicale étaient les suivants : la demande faisait état de douleurs aux membres inférieurs comme symptôme principal ou décrivait un déficit neurologique à l'examen physique et les rapports d'imagerie (CT ou IRM) montraient une compression d'une racine nerveuse. Ces demandes étaient considérés comme appropriés. Celles qui rapportaient des douleurs au dos et aux membres inférieurs sans spécifier quelle douleur était la plus intense, sans mentionner de déficit neurologique, et qui mentionnaient une compression possible d'une racine nerveuse dans le rapport d'imagerie étaient considérés comme incertaines. Celles qui ne mentionnaient pas de symptômes au niveau des membres inférieurs ou de signes de déficit neurologique et/ou ne contenaient pas de description de compression d'une racine nerveuse à l'imagerie étaient considérées comme inappropriées. Résultats : Quatrevingt (26\%) des 303 requêtes pour une évaluation chirurgicale étaient appropriées, 92 (30\%) étaient incertaines et 131 (44\%) étaient inappropriées . Conclusions : Les médecins qui dirigent des patients qui présentent des symptômes lombaires vers des spécialistes doivent être mieux informés des critères qui indiquent qu'un traitement chirurgical serait approprié, soit des observations cliniques et radiologiques de compression d'une racine nerveuse. Le fait d'éviter de diriger des patients pour lesquels une telle évaluation est inappropriée pourrait diminuer le temps d'attente tant pour la consultation en chirurgie que pour la chirurgie lombaire pour les patients chez qui elle est indiquée.

Can. J. Neurol. Sci. 2010; 37: 843-848

Patients with degenerative lumbar spine disease constitute a significant proportion of referrals to neurosurgeons, the typical chief complaint being midline low back pain. Low back pain is prevalent in North America, with an estimated lifetime incidence between 50 and $84 \%{ }^{1-5}$. Chronic low back pain is associated with significantly increased healthcare utilization involving both primary care providers and specialists ${ }^{6,7}$. The underlying cause of low back pain is usually nonspecific and strongly influenced by psychological and social factors ${ }^{8,9}$. Patient education, physical therapy and anti-inflammatory medications are the mainstays of treatment, and referral for surgical assessment is recommended only for patients with persistent symptoms and signs of nerve root compression despite a trial of medical management ${ }^{10}$. Acceptance of referral guidelines such as these is variable $\mathrm{e}^{11-14}$, and there is some evidence that many patients lacking surgical disease are nevertheless referred for surgical assessment ${ }^{15}$. Because of the great number of lumbar spine referrals received by surgeons, patients may wait months before

From the Department of Surgery, Division of Neurosurgery, University of Alberta Hospital, Edmonton, Alberta, Canada.

Received March 25, 2010. Final Revisions Submitted May 27, 2010. Correspondence to: J. Max Findlay, Department of Surgery, Division of Neurosurgery, University of Alberta Hospital, 2D1.02 WMC, 8440-112 Street, Edmonton, Alberta, T6G 2B7, Canada. 

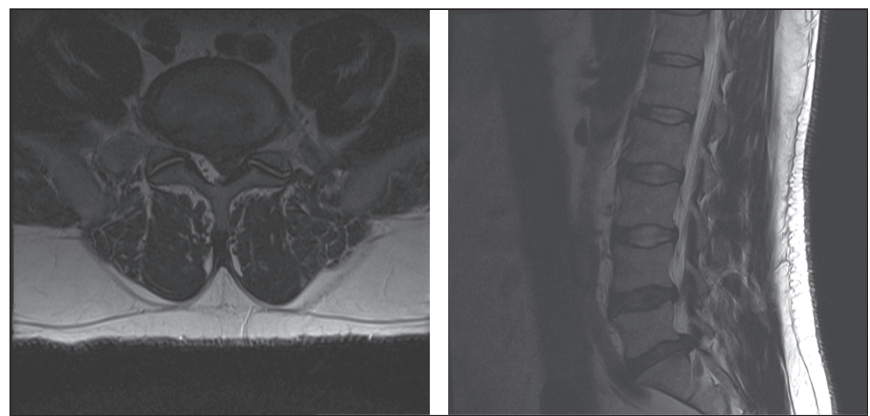

Figure 1: Transverse (left) and sagital (right) views of a large L5-S1 disk protrusion on T2 MRI sequences. The S1 nerve root on the patient's left is compressed.

evaluation, during which time their lives and livelihoods may have been placed "on hold"16-18.

Surgeons rely on referral letters to triage patients to be seen in outpatient clinics and timely consultations depend on information provided by primary care physicians. This study was undertaken to determine the appropriateness of outpatient lumbar spine referrals to a group of neurosurgeons serving northern Alberta.

\section{METHODS}

\section{Data collection}

All lumbar spine referrals to the entire group of ten neurosurgeons in Edmonton, Alberta who practiced adult spine surgery were collected over three eight - week periods in 2007 , 2008 and 2009. Patients with known or suspected neoplasia or acute trauma were excluded. Data collected included the following: the chief complaint (back versus leg pain, or both where the greater pain was unspecified); the presence or absence of signs of neurological deficit(s); and the results of spinal imaging either on computed tomography (CT) or magnetic resonance imaging (MRI). The University of Alberta Health Research Ethics board granted approval for this study.
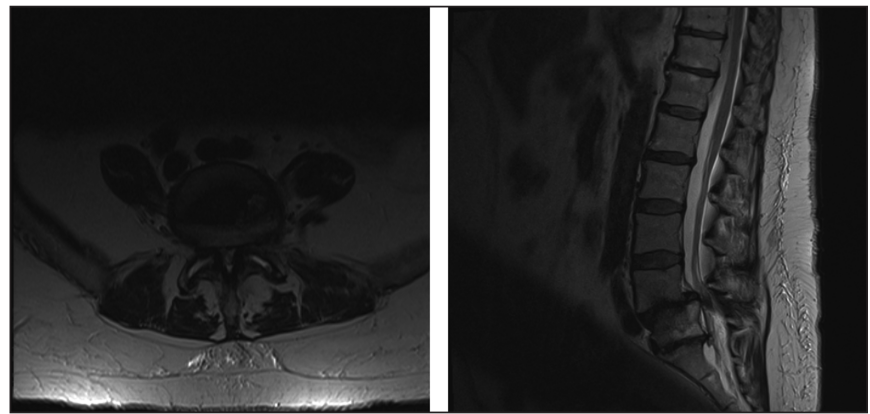

Figure 3: Transverse (left) and sagital (right) T2 MRI views of a patient with Grade 1 degenerative spondylolisthesis at L4-L5. The deformity, and the associated disc herniation and facet hypertrophy, cause significant spinal stenosis and nerve root compression.
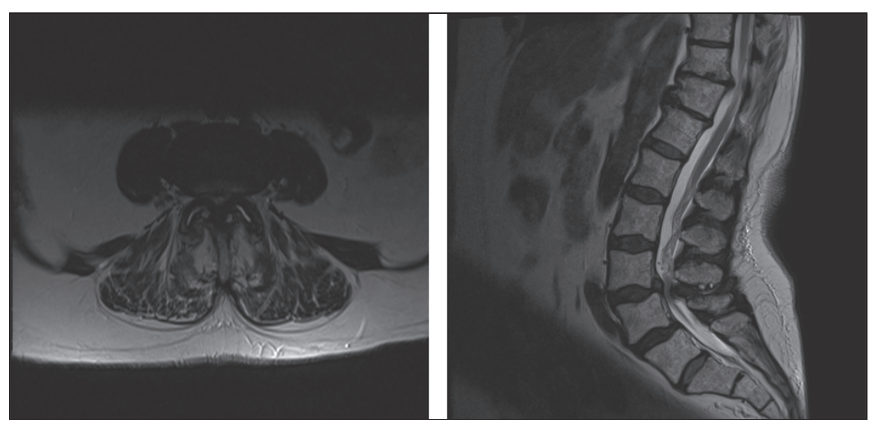

Figure 2: Transverse (left) and sagital (right) T2 MRI views of a patient with severe spinal stenosis at L3-L4. There is severe hypertrophy of the ligamentum flavum as well as a mild disk bulge causing bilateral stenosis of the lateral recesses and neural foramina. The thecal sac is compressed and there is impingement of multiple nerve roots.

\section{Assessment of referrals}

Pain location and principal pain location was determined from referral letters. For the purpose of this study "paresthesiae" and "dysesthesiae" were interpreted as pain symptoms, but complaints of numbness alone were not. Occasional reports of "buttock" or "hip" pain was interpreted as part of back pain when mentioned along with co-existing back pain, and as part of leg pain when mentioned along with co-existing leg pain. Patients included in the entire study group referred to one of the ten surgeons (the senior author) were classified by both referral information and then again following consultation based on actual clinical information and findings obtained directly from patients, and in this reclassification were judged as either appropriate or inappropriate based on the presence or absence of symptoms and/or signs of nerve root compression with corresponding imaging.

Imaging results were not viewed by the investigators but rather obtained from radiology reports, and they were categorized as "positive", "possible", or "negative" for nerve root compression. Positive imaging reports included any of the following descriptions (or combinations thereof): 1) a large
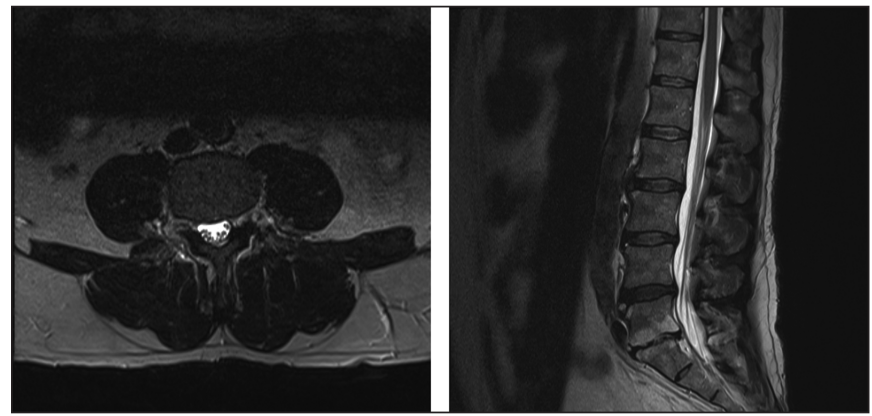

Figure 4: Transverse (left) and sagital (right) T2 MRI views of a patient with mild degenerative changes in the lumbar spine. There are mild disk bulges at L4-L5 and at L5-S1. At L5-S1 there is significant loss of disc height as well as degenerative changes in the vertebral body endplates, however there is no nerve root compression. 
Table 1: Lumbar spine complaints and appropriateness for surgical assessment

Appropriate
$\begin{aligned} & \text { Referral letter includes one or more of the following: } \\ & \text { Leg pain, rather than back pain is specified as the chief complaint } \\ & \text { described as the chief complaint } \\ & \text { Physical exam evidence of nerve root deficit (reduction/loss of motor } \\ & \text { power/reflex, altered sensation including numbness, parasthesia or dysesthesia), } \\ & \text { or positive straight leg raise is described }\end{aligned}$
$\begin{aligned} & \text { Plus: } \\ & \text { Imaging (CT or MRI) is positive for nerve root compression }\end{aligned}$
Referral letter includes both of the following:
Leg pain (including claudication) and spinal back pain are mentioned, but the
principal pain is not specified
Plus/Or

intervertebral disk herniation or bulge; 2) severe spinal stenosis; 3) spondylolisthesis (vertebral body slippage); and/or 4) any degenerative change or lesion specifically described as causing compression of a nerve root or roots (Figures 1-3). Imaging classified as possibly causing nerve root compression were those reports that described more moderate pathologies without definite evidence of nerve root compression ("mild to moderate central spinal stenosis" or "foraminal stenosis" being the commonest examples), and negative imaging reports were those where the radiologist specifically stated that there was no evidence of nerve root compression (Figure 4). In cases where there was uncertainty about the radiology report imaging was classified with a bias towards being positive for pathology. Clinical information and the results of the imaging reports were then used to categorize referrals as either "appropriate for surgical assessment", "uncertain for surgical assessment" or "inappropriate for surgical assessment" as shown in Table 1. Chi square analysis was used to determine dependency between various patient characteristics and appropriateness for surgical assessment. All statistics were performed using InStat ${ }^{\circledR}$ software by GraphPad®.

\section{RESULTS}

There were 303 eligible lumbar spine referrals collected by the ten neurosurgeons over the study periods, 294 (97\%) from primary care physicians and the remainder from specialists. The mean age of referred patients was 55 years, and clinical data contained in the referrals are summarized in Table 2.

When appropriateness criteria were applied to the referrals, $131(44 \%)$ were inappropriate for surgical assessment, $92(30 \%)$ were uncertain and $80(26 \%)$ were appropriate. By definition all "appropriate" referrals had imaging that was positive for pathology causing nerve root compression, and 70\% clearly indicated leg pain as the chief complaint. The other $30 \%$ of "appropriate" patients did not specify limb pain as the main complaint but described neurological deficits and a potential nerve root deficit. Most "inappropriate" referrals (71\%) contained no evidence of root compression in terms of either pain location or physical findings, and the remaining $29 \%$ would have otherwise been classified as appropriate or uncertain for surgical assessment based on clinical information provided but had imaging that was negative for nerve root compression.

Thirty-five patients referred to and seen by the senior author were classified a second time following consultation and direct patient assessment. Based on referral information 9 (26\%) were first classified as appropriate, $12(34 \%)$ were uncertain and 14 $(40 \%)$ were inappropriate. Following consultation and reclassification $20(57 \%)$ were considered appropriate, or in other words thought by the senior author to be suffering in part or in whole of true nerve root compression, and 15 (43\%) were inappropriate, meaning they had no complaints considered referable to nerve root compression. 


\section{Table 2: Clinical data from referral letters}

\begin{tabular}{ll}
\hline Gender & $\begin{array}{l}\text { Number of Patients } \\
\text { (percentage) }\end{array}$ \\
Male & $172(57 \%)$ \\
Female & $131(43 \%)$ \\
Municipality & $141(47 \%)$ \\
Urban & $162(53 \%)$ \\
Rural & \\
Chief complaint: & $88(29 \%)$ \\
Leg pain & $67(21 \%)$ \\
Back pain & $114(37 \%)$ \\
Back and Leg pain (principal pain unclear) & $34(12 \%)$ \\
No Symptoms/Complaints Described & \\
\hline Physical Exam: & $238(79 \%)$ \\
None provided & $51(17 \%)$ \\
Positive for nerve root findings & $14(4 \%)$ \\
Negative for nerve root findings & \\
\hline Imaging Provided: & $184(61 \%)$ \\
MRI & $88(29 \%)$ \\
CT & $9(3 \%)$ \\
Plain Films & $22(7 \%)$ \\
No Imaging: & \\
\hline
\end{tabular}

There was no significant difference in the appropriateness of referrals from the city of Edmonton and those from smaller communities $(p=0.54)$. The likelihood of having an MRI scan for assessment was slightly higher for patients living in Edmonton compared to all others (OR 1.4), a difference that was not significant $(p=0.17)$. Appropriateness of referral did not depend on patient gender $(p=0.91)$. Three of the ten neurosurgeons included in this study have a complex spine practice, and collectively they received 134 (44\%) of the referrals. There was no difference in the appropriateness of referrals to these surgeons and the others $(\mathrm{p}=0.32)$.

\section{DISCUSSION}

Patients suffering from persistent lumbar radiculopathy after a period of conservative management of analgesia, antiinflammatory agents and reduced activity are appropriate candidates for surgical consultation. These patients have leg pain as opposed to back pain as their chief complaint, and many will have accompanying neurological deficits, such as weakness of great toe dorsiflexion in the case of an L5 nerve root compression or loss of an ankle reflex in the case of a S1 nerve root compression. In our region $44 \%$ of back referrals to neurosurgeons in the time periods we studied appeared inappropriate for surgery, without any clinical description of radiculopathy or any radiological evidence of nerve root compression. In this group of inappropriate referrals the chief complaint was seldom stated and in the majority (79\%) there was no mention of physical examination findings. Many inappropriate referrals consisted of a radiological report without any clinical information. Our experience is not unique; other outpatient neurosurgical practices have reported offering surgery to only $20 \%$ of patients referred for surgery ${ }^{15,17}$.
In our study imaging results were more frequently reported than other any other piece of clinical information. In our health care region access to $\mathrm{CT}$ and MRI is readily available to primary care physicians and the results of either is required as part of a referral for a lumbar spine complaint. It could be argued that interpretation of the imaging as "surgical" or "non-surgical" based on radiology reports is beyond the expertise of primary care physicians, particularly in view of the fact that up to $90 \%$ of patients over the age of 50 will have evidence of at least some degenerative lumbar spine disease on spinal imaging ${ }^{19,20}$. Lumbar spine CT and MRI reports are often positive for some abnormality, and providing there was at least some mention of leg pain or neurological deficits referrals in our study were classified as either appropriate or uncertain for surgical assessment. Degenerative abnormalities associated with only back pain and without evidence of radiculopathy, were classified as inappropriate for surgical assessment, a judgment we believe within the scope of primary care assessment. We found that most inappropriate referrals (nearly three-quarters) were based on lack of symptoms or signs of radiculopathy rather than negative lumbar spine imaging.

An audit similar to ours, performed in an outpatient neurosurgical clinic in Australia, found $27 \%$ of referrals inappropriate due to lack of radicular symptoms of a limited symptom duration ${ }^{15}$, and since positive lumbar spine imaging was not a criterion (since most patients had imaging ordered only following surgical consultation) these results are close to our finding of $33 \%$ inappropriate referrals when imaging was not considered. We did not include symptom duration in our appropriateness criteria since the time for patients to obtain imaging and reach neurosurgical consultation in our region takes a minimum of several months. Mayman and Yen studied the outcome of 142 outpatient visits to Canadian spine surgeons for lumbar spine problems ${ }^{17}$. Only $19 \%$ were considered candidates for decompressive surgery, and the remainder had pain not considered remedial by surgical measures for a variety of reasons. A recent Canadian study demonstrated that clearly back-dominant pain as determined from a patient questionnaire was $100 \%$ sensitive for determining patients with non-surgical disease $^{21}$. No patients who described their pain as primarily in their back in a simple three-item questionnaire were offered an operation after surgical assessment. Eliminating this group of "inappropriate referrals" would have decreased surgical consultations by $43 \%{ }^{21}$.

Measures to improve the appropriateness of lumbar spine referrals to surgeons have been employed by others and with some success. These include screening clinics in which patients are assessed and additional tests or consultations (including consultations to surgeons) are arranged when indicated ${ }^{22-24}$. Educational programs targeting primary care physicians have had variable results ${ }^{25,26}$. Dissemination of referral guidelines has not significantly changed practice patterns ${ }^{13,27}$, but educational interventions including seminars and local experts may have a greater impact ${ }^{27,28}$. The use of standardized referral forms has also been shown to improve appropriateness of referrals to specialists $^{27}$.

Lumbar spine fusion, usually involving internal instrumentation and fixation, has an important role in the management of spinal instability due to trauma, neoplasia and 
severe congenital or degenerative deformities ${ }^{29-32}$. Spinal fusion to treat mechanical back pain has been practiced, but without clear evidence of effectiveness ${ }^{33-38}$. Spinal fusion is not recommended for the population of patients we chose to examine and so was not addressed in this study. Some surgeons would argue that in the specific case of spinal instability due to deformity such as spondylolisthesis, surgery would be indicated if there is resulting spinal pain with or without radiculopathy. These however constitute a minority of degenerative spine referrals. We tracked referrals with spondylolisthesis described in the radiology reports for the first 263 referrals. Of these 12 had spondylolisthesis of about $25 \%$ or greater. A number of these patients had radicular pathology and were classified as appropriate and uncertain (four and two respectively). Had we excluded these patients with significant deformity our results (27\% appropriate, $30 \%$ uncertain, $43 \%$ inappropriate) would have been essentially identical.

Certain patients who clearly do not have surgical pathology may still wish to meet with a surgeon to discuss possible options for their care, despite being informed they do not have a surgical problem. We do not suggest that surgeons refuse to see such patients, but rather that the referring physician should be aware of the likelihood that surgery will not be offered and this should be discussed with the patient beforehand so that they have reasonable expectations for the clinic visit, wait time and outcome.

Our study only used referral letter information and radiology reports to determine the appropriateness of lumbar spine referrals. This has an important limitation in that it is difficult to know if "inappropriate" referrals were the result of actual patient characteristics, misrepresentation of clinical features, or both. This same challenge is faced in day-to-day neurosurgical practice. We attempted to address this issue by reclassifying 35 patients included in our study following direct neurosurgical assessment by the senior author. This reclassification eliminated the "uncertain" group as these patients were divided into either appropriate or inappropriate patients for surgical assessment based on direct evidence of nerve root compression as determined by expert assessment. In this subgroup $43 \%$ of the 35 patients remained inappropriate referrals, virtually the same as the $44 \%$ of the entire group judged on the merits of referral information alone. None of the 14 "inappropriate" referrals reviewed by the senior author were considered "appropriate" after direct assessment. However it remains possible that in the whole group of study referrals assessed, some patients classified as inappropriate for surgical assessment might have been "uncertain" or even "appropriate" based on additional information not included in referral information, such as the presence of leg pain in addition to back pain, or the presence of a mild neurological deficit that was either not detected or mentioned. Another limitation of our study was that spinal imaging (CT or MRI) was required before referral to a neurosurgeon, so all patients included in the study had imaging reports to include in our analysis. In our practice setting the most streamlined approach to providing spine care is for imaging referrals to be done by the primary care physician, since the wait time for specialist consultation is far longer than for CT or MR imaging. Education and feedback to referring physicians regarding the role of imaging in spine care is paramount to ensure effective use of CT and MRI. Still in some regions of Canada it may remain difficult or impossible for patients to undergo spinal imaging without a request from a specialist. We believe our findings still have some relevance to primary physicians in those jurisdictions, however, since we found the large majority of inappropriate referrals (the important group to avoid surgical consultation for) were so designated on the basis of clinical symptoms and signs inconsistent with nerve root compression, not on the basis of a CT or MRI report.

\section{Conclusions}

Referrals of patients complaining only or mainly of back pain, with no neurological deficits and imaging results that are either normal or showing age - related degenerative lumbar spine changes without definite nerve root compression are inappropriate for surgical assessment. The apparent "inappropriateness" of so many referrals to surgeons in our centre highlights the disconnection between reasons for referral and the indications for surgery. Spine surgeons could do better in informing referring physicians about the role for surgery in patients with spine related complaints. Effective education strategies need to be explored in order to avoid unnecessary referrals and improve access for those patients who would benefit most.

\section{REFERENCES}

1. Manchikanti L, Singh V, Datta S, Cohen SP, Hirsch JA, Physicians ASoIP. Comprehensive review of epidemiology, scope, and impact of spinal pain. Pain Physician. 2009; 12(4): e35-70.

2. Cassidy JD, Carroll LJ, Côté P. The Saskatchewan health and back pain survey. The prevalence of low back pain and related disability in Saskatchewan adults. Spine. 1998; 23(17): 1860-6.

3. Freburger JK, Holmes GM, Agans RP, et al. The rising prevalence of chronic low back pain. Arch Intern Med. 2009; 169(3): 2518.

4. Kalichman L, Cole R, Kim DH, et al. Spinal stenosis prevalence and association with symptoms: the Framingham Study. Spine J. 2009; 9(7): 545-50.

5. Licciardone JC. The epidemiology and medical management of low back pain during ambulatory medical care visits in the United States. Osteopath Med Prim Care. 2008; 2: 11.

6. Lim K-L, Jacobs P, Klarenbach S. A population-based analysis of healthcare utilization of persons with back disorders: results from the Canadian Community Health Survey 2000-2001. Spine. 2006; 31(2): 212-8.

7. Chenot J-F, Leonhardt C, Keller S, et al. The impact of specialist care for low back pain on health service utilization in primary care patients: a prospective cohort study. Eur J Pain. 2008; 12(3): 275-83.

8. Melloh M, Elfering A, Egli Presland C, et al. Identification of prognostic factors for chronicity in patients with low back pain: a review of screening instruments. Int Orthop. 2009; 33(2): 301-13.

9. Jain R. Pain and the brain: lower back pain. J Clin Psychiatry. 2009; 70(2): e41.

10. Chou R, Qaseem A, Snow V, et al. Diagnosis and treatment of low back pain: a joint clinical practice guideline from the American College of Physicians and the American Pain Society. Ann Intern Med. 2007; 147(7): 478-91

11. Buchbinder R, Staples M, Jolley D. Doctors with a special interest in back pain have poorer knowledge about how to treat back pain. Spine. 2009; 34(11): 1218-26.

12. Corbett M, Foster N, Ong BN. GP attitudes and self-reported behaviour in primary care consultations for low back pain. Fam Pract. 2009; 26(5): 359-64. 
13. Rao JK, Kroenke K, Mihaliak KA, Eckert GJ, Weinberger M. Can guidelines impact the ordering of magnetic resonance imaging studies by primary care providers for low back pain? Am J Manag Care. 2002; 8(1): 27-35.

14. González-Urzelai V, Palacio-Elua L, López-de-Munain J. Routine primary care management of acute low back pain: adherence to clinical guidelines. Eur Spine J. 2003; 12(6): 589-94.

15. Huang JG, Huang GH, Teddy PJ. Low back pain in neurosurgical outpatients: an audit. J Clin Neurosci. 2008; 15(11): 1216-21.

16. Hurlbert RJ, Mobbs R, Teo C. Access to spine care: a tale of two cities. Can J Neurol Sci. 2008; 35(3): 308-13.

17. Mayman D, Yen D. Maximizing use of a surgical clinic for referrals of patients having back problems. Can J Surg. 1999; 42(2): 1179.

18. Rossignol M, Abenhaim L, Bonvalot Y, Gobeille D, Shrier I. Should the gap be filled between guidelines and actual practice for management of low back pain in primary care? The Quebec experience. Spine. 1996; 21(24): 2893-8; discussion 2898-9.

19. Hicks GE, Morone N, Weiner DK. Degenerative lumbar disc and facet disease in older adults: prevalence and clinical correlates. Spine. 2009; 34(12): 1301-6.

20. Cheung KMC, Karppinen J, Chan D, et al. Prevalence and pattern of lumbar magnetic resonance imaging changes in a population study of one thousand forty-three individuals. Spine. 2009; 34(9): 934-40.

21. Simon D, Coyle M, Dagenais S, O'Neil J, Wai EK. Potential triaging of referrals for lumbar spinal surgery consultation: a comparison of referral accuracy from pain specialists, findings from advanced imaging and a 3-item questionnaire. Can J Surg. 2009; 52(6): 473-80.

22. Mofidi A, Sedhom M, O'Shea K, et al. Screening of lower back pain, low back pain clinic. The clinical experience. Ir Med J. 2003; 96(9): 270-3.

23. Klein BJ, Radecki RT, Foris MP, Feil EI, Hickey ME. Bridging the gap between science and practice in managing low back pain. A comprehensive spine care system in a health maintenance organization setting. Spine. 2000; 25(6): 738-40.

24. Harrington JT, Dopf CA, Chalgren CS. Implementing guidelines for interdisciplinary care of low back pain: a critical role for preappointment management of specialty referrals. Jt Comm J Qual Improv. 2001; 27(12): 651-63.

25. Fullen BM, Baxter GD, O'Donovan BGG, Doody C, Daly LE, Hurley DA. Factors impacting on doctors' management of acute low back pain: a systematic review. Eur J Pain. 2009; 13(9): 908-14.
26. Dey P, Simpson CWR, Collins SI, et al. Implementation of RCGP guidelines for acute low back pain: a cluster randomised controlled trial. Br J Gen Pract. 2004; 54(498): 33-7.

27. Grimshaw JM, Winkens RAG, Shirran L, et al. Interventions to improve outpatient referrals from primary care to secondary care. Cochrane Database of Syst Rev. 2005; (3): CD005471.

28. Schectman JM, Schroth WS, Verme D, Voss JD. Randomized controlled trial of education and feedback for implementation of guidelines for acute low back pain. J Gen Intern Med. 2003; 18(10): 773-80.

29. Jones TR, Rao RD. Adult isthmic spondylolisthesis. J Am Acad Orthop Surg. 2009; 17(10): 609-17.

30. Fourney DR, Gokaslan ZL. Spinal instability and deformity due to neoplastic conditions. Neurosurg Focus. 2003; 14(1): e8.

31. Buchowski JM, Kuhns CA, Bridwell KH, Lenke LG. Surgical management of posttraumatic thoracolumbar kyphosis. Spine J. 2008; 8(4): 666-77.

32. Glaser J, Stanley M, Sayre H, Woody J, Found E, Spratt K. A 10year follow-up evaluation of lumbar spine fusion with pedicle screw fixation. Spine. 2003; 28(13): 1390-5.

33. Schafer J, O'Connor D, Feinglass S, Salive M. Medicare Evidence Development and Coverage Advisory Committee Meeting on lumbar fusion surgery for treatment of chronic back pain from degenerative disc disease. Spine. 2007; 32(22): 2403-4.

34. Mirza SK, Deyo RA. Systematic review of randomized trials comparing lumbar fusion surgery to nonoperative care for treatment of chronic back pain. Spine. 2007; 32(7): 816-23.

35. Gibson JN, Waddell G, Grant IC. Surgery for degenerative lumbar spondylosis. Cochrane Database Syst Rev. 2000; (3): CD001352.

36. Gibson JNA, Waddell G. Surgery for degenerative lumbar spondylosis: updated Cochrane Review. Spine. 2005; 30(20): 2312-20.

37. Tsang IK. Perspective on low back pain. Curr Opin Rheumatol. 1993; 5(2): 219-23.

38. Brox JI, Reikerås $\mathrm{O}$, Nygaard $\varnothing$, et al. Lumbar instrumented fusion compared with cognitive intervention and exercises in patients with chronic back pain after previous surgery for disc herniation: a prospective randomized controlled study. Pain. 2006; 122(12): $145-55$ 